$\xi=-1$

\title{
A survey of mobile cloud computing offloading concepts based on measurements and algorithms
}

\author{
SK. Piramu Preethika ${ }^{1} *$, R. Gobinath ${ }^{2}$ \\ ${ }^{1}$ Research scholar, Department of Computer Science, Vels Institute of Science, Technology and Advanced Studies \\ (VISTAS), Chennai, India. \\ ${ }^{2}$ Assistant Professor, Vels Institute of Science, Technology and Advanced Studies (VISTAS), Chennai, India. \\ *Corresponding author E-mail: iamgobinathmca@gmail.com
}

\begin{abstract}
Handheld computing devices at the moment everywhere in the arms of generation dependent human beings of every age. Clients are looking for new innovative thoughts to first and best utilization of Smart Mobile Devices. The rapid enlargement of the number of clever telephone users has given rise of various research subjects. While the technological advancements are happening from hardware and package levels, novel ideas are being introduced. One amongst those ideas is Mobile Cloud computing which is the mix of cloud computing, mobile compu-ting and wireless networks to bring wealthy process resources to mobile users, network operators, yet as cloud computing suppliers. MCC offloading is a technique to overcome the barriers like battery life, memory usage, computation difficulties faced in Mobile computing with the help of cloud. This survey not only focuses on the concepts of offloading, it also concentrates on the measurements and basic ideas of Mobile Cloud computing related algorithms.
\end{abstract}

Keywords: Smart Mobile Device (SMD); Mobile Computing; Cloud Computing; Mobile Cloud Computing (MCC).

\section{Introduction}

In human life, basic needs are water, air, food, place now Smart mobile Devices occupies the fifth place. Recent years the growth graph of computers started from Desktop to Main frames, Main frames to Basic Mobiles; Basic Mobiles to Smart Phones, IPad, IPod, tablets, Note books and so on. As we are in the information era, modern compact handheld devices with slim and slick design, high-resolution camera, Siri (voice support) like internet helpers, rich graphics adaptors multidisciplinary sensors, resourceful operating system were made people addict to them. SMD is the entertainer of all age group. Mobiles not only entertain people but also make them knowledgeable in all aspects with the help of internet facility. But the drawback here is high usage of internet leads to low battery. This will affect the mobile performance.

The advances in Smartphone hardware are unable to cater to users/applications computational control and force demands as they are tiny in size [1] [32]. The need for "information anywhere anytime" has been a power house for the mounting growth in web and net innovation, wireless communication, and movable computing devices. Wireless communication faces more blockages than wired communication because the surrounding atmosphere cooperates with the signal, overcrowding signal paths and introducing noise and echoes. As a result, lesser bandwidths, higher inaccuracy rates, and more recurrent unauthentic disconnections [2], [31], differentiate wireless contact.

Cloud Computing is the pool of heterogeneous resources can be utilized by the user on-demand as pay per use. Aim of cloud computing is to maximize the usage that may be resource, infrastructure, software, hardware with a minimum cost [3]. Few years later, emergence of cloud resources constructed an opportunity to mitigate the shortcomings of utilizing surrogates in augmenting mobile devices. Cloud is a type of distributed system comprised of a bunch of powerful computers easily reached as unified computing resource(s) based on a Service Level Agreement (SLA) [4] [33].

1) Mobile computing

Mobile Computing is a process which allows the people to collect the data from anywhere and anytime with the help of devices like smart phones, PDA, Tablet, Fablet, Laptop and Wearable computers, such as the Apple Watch. It transmits information, sounds and prerecorded clipings.Exchange of data from handheld device to the internet via radio waves is achieved thru wireless technology.

2) Mobile Constraints

- Mobile Device Constraints: Mobile devices have restricted resources like processor speed, memory and display size and resolution as they are tiny in size. Those devices could have microphone or pen point screen to interact with the users to beat the above noted drawbacks.

- Network Constraints: Wired networks having more reliability than wireless networks. Lower bandwidth, higher latency and more disconnection these affects the wireless networks. If bandwidth increases then energy consumption also raises, this leads to decrease the battery time of smart portable devices. Hence, efficacy of data throughput to and from SMD will be limited even if wireless networks connections deliver stable higher bandwidth.

- Mobility Constraints: Mobile elements are resource-poor related to static components, Mobility is naturally hazardous, Mobile connectivity is highly variable in performance and reliability. 
3) Issues of mobile computing

Issues in mobile computing can be categorized into three

Major areas as communication, mobility, and portability.

a) Wireless Communication- 1.Disconnections, 2. Low Bandwidth and Bandwidth Variability, 3. Security Risk

b) Mobility-1.Address Migration, 2. Location dependent Information

c) Portability- 1. Low Power, 2. Small User Interface,Small Storage Capacity

\section{Wireless sensor network (WSN)}

To solve the major communication issues in defense, civil and industrial WSN has a key .The inclusion of sensor-mobility with WSN has broadened application horizon. The effectiveness of WSNs can be characterized by its ability to perform efficient data gathering and transmission to the base station for decision process [5].

\section{MCC implementation with cloud compu- ting}

Mobile cloud applications move the computing power and data storage space away from mobile phones into the cloud, hand shack with Smart phone subscribers but a much broader range through telecommunication. The need for a mobile cloud is as follows: Image processing, Natural language processing, Crowd computing, Distribution GPS/Internet data, sensor data functions, multimedia exploration, social networking [6].

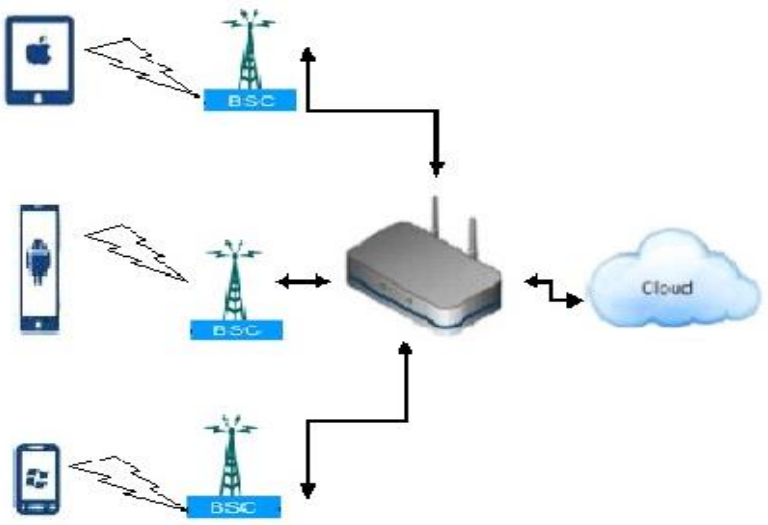

Fig. 1: General View of Mobile Cloud Computing.

MCC does not make the cloud computing "movable" but as a surrogate, it can be a Wi-Fi extension of cloud provider centers. MCC gives support to the mobile user by providing rich functionality cloud usage as per demand and with minimum utilization cost. Mobile Cloud Computing is interrelated to cellular phone users, Mobile service providers, Cloud Service Providers. It provides an autonomous digital environment to SMD to get effective storage and service and complex computation exact. Wirelessly connected devices use the optimized path to net and access the cloud to solve their complex problems. The Cloud supports the SMD to overcome all its barriers like scheduling, resource Utilization, speed up the process, security but stable at one place. Every SMD use batteries which affect the growth curve of mobile cloud computing.

\section{MOBILE cloud computing offloading}

Mobile Systems having limited Resources like lower battery life, low bandwidth, less storage space and very less processor performance leads to Computation Offloading. Migrating programs to servers is called as Computation offloading. The terms "cyber foraging" and "surrogate computing" is as well as used to enlighten computation offloading. Computation offloading is a technique which leads to the path of efficiency in performance and increases the energy consumption. Problems of SMD can be beat by shift the computation part to the rich resourceful remote servers and then retrieve results from these servers to mobile devices.

1) Objectives of offload

This reduces execution time, to save energy and to describe infrastructure \& tools to address offload. The resolutions are usually made by scrutinize parameters including bandwidths, server speeds, accessible memory, server stacks, and the quantity of data exchanged between servers and mobile systems. The consequences include visioning of programs forecasting parametric deviations in application deeds and implementation environment.

2) Forms of Computation offloading

- Partial Offloading: In this type of offloading large computation intensive assignments are performed on a virtual machines and remaining tasks executed on SMD. Results attained from both VM and SMD provided to the user in a needed format.

- Complete offloading: In case of complete offloading whole application is reserved on cloud and that act as an accurate replica of the SMD with the same utility. The drawback of this type architecture is that the applications that fit into this architecture are very less.

- Task offloading: This type of offloading performs a sequence of tasks or a step of an application.

- Code offloading: An exact part of an application that may be an object, function or a class will be offloaded to the distant server in the cloud.

3) Computation offloading Stages

Stages of Computation Offloading classified into Partitioning, make a decision, whether and what computation to roam. Before start the process a complete execution analysis is taken place whether offloading can be effective or not by calculating the time duration (sending, waiting and retrieval), and also the cost to migrate must be less than execution cost in SMD. There are two main approaches for offloading computation from mobile devices to the external resources. The first approach is to partition the application and outsource part of the code to the remote servers based on available resources, such as network availability, bandwidth, and latency.

a) Apply Program Partitioning

First step of partitioning is identifying the part to be offloaded to the cloud. Partitioning programs can be done in following ways.

- VM Migration: In this entire state of VM relocated to server and in, VM synthesis a tiny part is sent which leads to heavy computation in local machine.

- Method Level: Here partitioning state associated with this also transmitted to the server.

- Thread Level: Here fewer circumstances are necessitating to be reassigned among client and server machine.

b) Make a Decision

There are two decisions such as static offloading or dynamic offloading. In Static offloading, decision parameters are described at design time while in case of dynamic offloading decision parameters are illustrated at run time of an application. The later approach is to forward the entire application through virtual machine migration. Therefore, at runtime, system knows which piece of program should be offloaded. Static offloading cannot guarantee to present the preeminent partitioning for all possible situations. Spectra and Chroma is the most imperative works that do partitioning prior to program carrying out. In distinguish dynamic offloading starts to offload tasks when one of the required resources is inadequate and divide the program according to the availability of resources at runtime. This approach decides on offloading based on present circumstances and is therefore more flexible. And moreover it creates additional overheads on the system relating to latency, profiling 
and run-time decision making that can lead to needless offloading too.

4) Challenges of offloading

Different challenges associated with computation offloading and mobile cloud computing.

a) Secure data on Cloud: User privacy is a main thread in MCC.Different SMD owner's access the same cloud as they want to store their data and retrieve that for future usage. Authentication, digital right management arises.

b) Network Congestion: As many Mobile Users utilizing the cloud at the same time there comes network traffic, it affects the functionality of cloud.

c) Reliability: For effective computation offloading speed of the web is important. Restricted Choices are $3 \mathrm{G}$ and Wi-Fi. 3G has benefits because of its availability and speed however it consumes large amount of energy. But Wi-Fi put away s a reduction of power and has high bandwidth to permit computation offloading however it has a lesser amount of availability.

d) Heterogeneity: dissimilar mobile devices to admit services obtainable by the cloud use Radio access technologies like WCDMA, WiMAX, GPRS, WLAN and CDMA2000.

e) Bandwidth Latency: The shortening of wireless network access technologies with large speed and latency is a foremost issue.

\section{Comparative study}

Table 1. Compare the issues of mobile computing and cloud computing and derive a conclusion that while in cloud computing multi-objective optimization algorithm and Virtual Machine load balancing algorithms have better response time than mobile computing. Table 2 worksout with Challenges like Energy Consumption, Performance parametric, Execution time, Optimization of mobile Com-puta-tions using Green Spot algorithm, Handoff decision algorithm, and PSO algorithms in mobile cloud computing. This table deals with comparison of three domains. If we combine any two different domains we can get the best from that two. Table 3 analyses the features of mobile computing; Cloud computing with Mobile cloud compu-ting. In Mobile computing Device energy is taken into ac-count of battery life. Computations can be executed in cloud saves the energy and life time of battery. Further if complex tasks are executed in mobile computing it takes more time it affects the functionality of mobile device but in MCC it's not an issue. Due to the mobili-ty of Mobile computing network disconnection may be occur however MCC overcomes network drawbacks. Moreover Mobile Computing joining hands with Cloud Computing gives better performance and security. We continue with MCC with implementation to cloud for better results. Table 4 studies the challenges on mobile cloud computing offload-ing using Adaptive Algorithm, Local Access Cloud of-floading Algorithm, Max Flow-Min Cut Algorithm, and Decentralized Computational mechanism. Table 5 investi-gates about the issues of offloading types. Dynamic Pro-gramming with Hamming Distance Termination (DPH) algorithm reached an optimal solution.

Table 1: Comparison of Mobile Computing and Cloud Computing Issues

\begin{tabular}{|c|c|c|c|c|}
\hline $\mathrm{SNO}$ & AUTHOR & TITLE & TOOLS / ALGORITHMS USED & MEASUREMENTS AND CHALLENGES \\
\hline 1 & $\begin{array}{l}\text { Dong Huang, Ping } \\
\text { Wang, Dusit Niyato }\end{array}$ & $\begin{array}{l}\text { A Dynamic Offloading Algo- } \\
\text { rithm for Mobile Computing [7] }\end{array}$ & $\begin{array}{l}\text { Dynamic offloading algo- } \\
\text { rithm(DOA),stand on Lyapunov } \\
\text { optimization }\end{array}$ & $\begin{array}{l}\text { DOA saves } 50 \% \text { of the energy where only } \\
20 \% \text { energy saved by remote execution }\end{array}$ \\
\hline 2 & $\begin{array}{l}\text { Ou, Shumao, Kun } \\
\text { Yang, and Jie } \\
\text { Zhang. }\end{array}$ & $\begin{array}{l}\text { An effective offloading mid- } \\
\text { dleware for pervasive services } \\
\text { on mobile devices[8] }\end{array}$ & $\begin{array}{l}(\mathrm{k}+1) \text { coarse partitioning algorithm, } \\
\text { Heavy-Edge and Light-Vertex } \\
\text { Matching (HELVM) algorithm }\end{array}$ & $\begin{array}{l}\text { Response time of Cached offloading is } 22.65 \\
\text { sec and Normal Offloading is } 25.40 \mathrm{sec} \\
\text { while mobile device response time is } 52.45 \\
\text { sec. }\end{array}$ \\
\hline 3 & $\begin{array}{l}\text { Shumao Ou, Kun } \\
\text { Yang, Antonio } \\
\text { Liotta and Liang Hu }\end{array}$ & $\begin{array}{l}\text { Performance Analysis of Of- } \\
\text { floading Systems in Mobile } \\
\text { Wireless Environments[9] }\end{array}$ & Sort Word Count algorithm & $\begin{array}{l}\text { Failure recovery time, total carrying out time } \\
\text { reduced. }\end{array}$ \\
\hline 4 & $\begin{array}{l}\text { Qi Liu, Weidong } \\
\text { Cai, Jian Shen, } \\
\text { Xiaodong Liu, } \\
\text { Nigel Linge, E }\end{array}$ & $\begin{array}{l}\text { An Adaptive Approach to Better } \\
\text { Load Balancing in a Consumer- } \\
\text { centric Cloud Environment[10] }\end{array}$ & $\begin{array}{l}\text { Virtual Machine load balancing } \\
\text { algorithms }\end{array}$ & $\begin{array}{l}\text { Completing time optimized. } \\
\text { Job Execution time using sort word algo- } \\
\text { rithm, dynamic strategy closes job } 12.5 \% \\
\text { faster than the native policy and } 9.5 \% \text { earlier } \\
\text { than strategy disabled do. }\end{array}$ \\
\hline 5 & $\begin{array}{l}\text { Soumya Ray and } \\
\text { Ajanta De Sarkar }\end{array}$ & $\begin{array}{l}\text { Execution analysis of load } \\
\text { balancing algorithms in cloud } \\
\text { computing environment[11] }\end{array}$ & & $\begin{array}{l}\text { Response time will be affected by millions } \\
\text { instructions per second. }\end{array}$ \\
\hline
\end{tabular}

Table 2: Comparative Study of Mobile Cloud Computing Challenges

\begin{tabular}{|c|c|c|c|c|c|c|}
\hline SNO & AUTHOR & TITLE & $\begin{array}{l}\text { TOOLS /ALGORITHMS } \\
\text { USED }\end{array}$ & \multicolumn{2}{|c|}{ CHALLENGES } & MEASUREMENTS \\
\hline 1 & $\begin{array}{l}\text { Abolfazli S, Sanaei } \\
\text { Z, Alizadeh M, Gani } \\
\text { A, Xia F }\end{array}$ & $\begin{array}{l}\text { An Experimental Analysis } \\
\text { on Cloud-Based Mobile } \\
\text { Augmentation in Mobile } \\
\text { Cloud Computing.[12] }\end{array}$ & $\begin{array}{l}\text { Resource-intensive Mo- } \\
\text { bile Applications } \\
\text { (RMAs) }\end{array}$ & b) & $\begin{array}{l}\text { Overall execution } \\
\text { costs (time and } \\
\text { energy) of RMAs. } \\
\text { c) Reduce Mobile } \\
\text { cloud Distance } \\
\text { enhances the per- } \\
\text { formance. }\end{array}$ & $\begin{array}{l}\text { Distance cloud reduces the } \\
\text { energy requirement from } \\
76.6 \% \text { to } 56.6 \%\end{array}$ \\
\hline 2 & $\begin{array}{l}\text { Namboodiri, V. and } \\
\text { Toolika, G. }\end{array}$ & $\begin{array}{l}\text { To Cloud or Not to Cloud: } \\
\text { A Mobile Device Perspec- } \\
\text { tive on Energy Consump- } \\
\text { tion of Applications[13] }\end{array}$ & $\begin{array}{l}\text { Green Spot Algorithm } \\
\text { used AppScore which } \\
\text { measures functionality } \\
\text { and performance }\end{array}$ & $\begin{array}{l}\text { a) } \\
\text { b) }\end{array}$ & $\begin{array}{l}\text { Power Consump- } \\
\text { tion minimized. } \\
\text { b) energy- } \\
\text { performance im- } \\
\text { proved. }\end{array}$ & $\begin{array}{l}\text { a) relative functionality, } \\
\text { performance of applica- } \\
\text { tions executed } \\
\text { b) Power Ratio calculated. }\end{array}$ \\
\hline 3 & $\begin{array}{l}\text { Amani S. Alnezari1, } \\
\text { Nasser-Eddine Rikli }\end{array}$ & $\begin{array}{l}\text { Achieving Mobile Cloud } \\
\text { Computing through Heter- } \\
\text { ogeneous Wireless Net- } \\
\text { works[14] }\end{array}$ & $\begin{array}{l}\text { The handoff decision } \\
\text { algorithm. } \\
\text { Offloading Decision } \\
\text { Engine(ODE) }\end{array}$ & $\begin{array}{l}\text { a) } \\
\text { b) }\end{array}$ & $\begin{array}{l}\text { Energy consump- } \\
\text { tion reduced. } \\
\text { b) Reduce applica- } \\
\text { tion execution } \\
\text { time. }\end{array}$ & $\begin{array}{l}\text { Execution time of intermediate } \\
\text { (3MB) or big image }(6.5 \mathrm{MB}) \\
\text { sizes will cost less in the } \\
\text { cloud. }\end{array}$ \\
\hline 4 & $\begin{array}{l}\text { Y.Padma, K.Pavan } \\
\text { Kumar, }\end{array}$ & $\begin{array}{l}\text { A Simple Analysis of Ser- } \\
\text { vice Oriented Architecture }\end{array}$ & $\begin{array}{l}\text { Cloud-based Mobile } \\
\text { Augmentation (CMA) }\end{array}$ & $\begin{array}{l}\text { Execu } \\
\text { gy col }\end{array}$ & $\begin{array}{l}\text { tion time and ener- } \\
\text { nsumption de- }\end{array}$ & $\begin{array}{l}\text { overall execution costs (time } \\
\text { and energy) of RMAs meas- }\end{array}$ \\
\hline
\end{tabular}




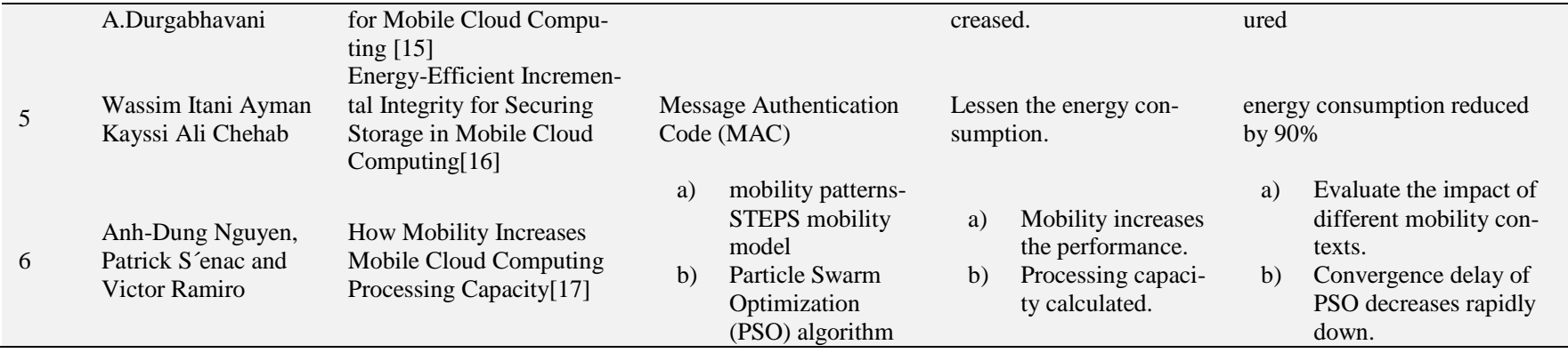

\begin{tabular}{llll}
\multicolumn{2}{c}{ Table 3: Mobile, Cloud and Mobile Cloud Computing Comparison. } \\
\hline Issues & Mobile Computing & Cloud Computing & Mobile Cloud Computing \\
\hline Device Energy & $\times$ & - & $\sqrt{ }$ \\
Bandwidth & $\times$ & $\sqrt{ }$ & $\sqrt{ }$ \\
Network Connectivity & $\times$ & $\sqrt{ }$ & $\sqrt{ }$ \\
Mobility & $\sqrt{ }$ & $\sqrt{ }$ & $\sqrt{ }$ \\
Security & $\sqrt{ }$ & $\times$ & $\sqrt{ }$ \\
Context Awareness & $\times$ & $\times$ & $\sqrt{ }$ \\
Location Awareness & $\sqrt{ }$ & $\times$ & \\
\hline
\end{tabular}

Table 4: Comparison of Challenges on Mobile Cloud Computing Offloading

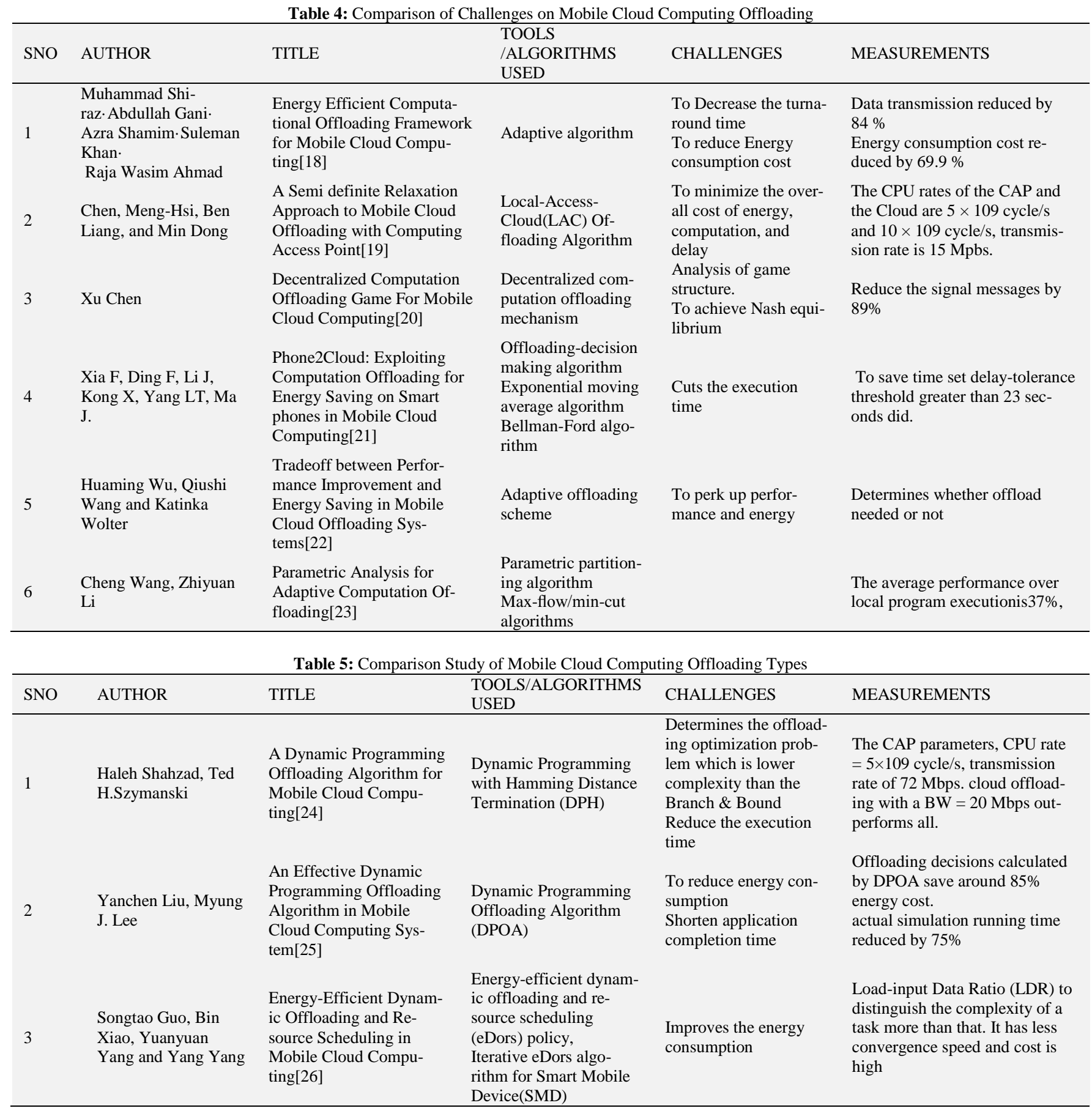




\begin{tabular}{|c|c|c|c|c|c|}
\hline 4 & $\begin{array}{l}\text { Eduardo Cuervo, } \\
\text { Aruna Balasubrama- } \\
\text { nian Dae-ki Cho, } \\
\text { Alec Wolman, Stefan } \\
\text { Saroiu, Ranveer } \\
\text { Chandra, Paramvir }\end{array}$ & $\begin{array}{l}\text { MAUI: Making } \\
\text { Smartphones Last Longer } \\
\text { with Code Offload[27] }\end{array}$ & $\begin{array}{l}\text { MAUI profiler,MAUI } \\
\text { solver }\end{array}$ & $\begin{array}{l}\text { Investigate offloading } \\
\text { issues. } \\
\text { Works on dynamic and } \\
\text { transparent offloading } \\
\text { to clouds. }\end{array}$ & $\begin{array}{l}\text { MAUI saves } 27 \% \text { power for } \\
\text { video gaming } 45 \% \text { to play chess. } \\
\text { Reduces latency by } 4.8 \text {; latency } \\
\text { cutback rate from } 6 \text { frames per } \\
\text { second to } 13 \text {. }\end{array}$ \\
\hline 5 & $\begin{array}{l}\text { Mohammed A. Has- } \\
\text { san, Kshitiz Bhat- } \\
\text { tarai, Qi Wei and } \\
\text { Songqing Chen }\end{array}$ & $\begin{array}{l}\text { POMAC: Properly Of- } \\
\text { floading Mobile Applica- } \\
\text { tions to Clouds[28] }\end{array}$ & $\begin{array}{l}\text { Dalvik virtual machine } \\
\text { (VM) }\end{array}$ & $\begin{array}{l}\text { Optimize the offloading } \\
\text { decision. }\end{array}$ & $\begin{array}{l}\text { User's reaction time with } \\
\text { POMAC is compact to } 59.39 \% \text {, } \\
1.00 \%, 11.99 \%, 72.28 \% \text {, and } \\
21.44 \% \\
\text { Energy consumed on SMD is } \\
57.21 \%, 9.49 \%, 25.80 \% \text {, } \\
90.01 \% \text {, and } 77.97 \%\end{array}$ \\
\hline 6 & $\begin{array}{l}\text { Jiwei Li Kai Bu } \\
\text { Xuan Liu Bin Xiao }\end{array}$ & $\begin{array}{l}\text { ENDA: Embracing Net- } \\
\text { work Inconsistency for } \\
\text { Dynamic Application } \\
\text { Offloading in Mobile } \\
\text { Cloud Computing[29] }\end{array}$ & $\begin{array}{l}\text { Greedy searching algo- } \\
\text { rithm } \\
\text { Delay offloading mech- } \\
\text { anism } \\
\text { Fault tolerant mecha- } \\
\text { nism }\end{array}$ & & $\begin{array}{l}\text { Data size less than } 58 \mathrm{Mb} \text { are } \\
\text { qualified. } \\
\text { Network latency affects offload } \\
\text { overhead. }\end{array}$ \\
\hline
\end{tabular}

\section{Conclusion}

This paper is a combined reference of the algorithmic mechanisms and the linked infrastructures, and identifies existing barriers and directions for research. This research carries the over the background, techniques, systems, and various types of offloading computation. In future, this work will be continued with dynamic offloading technique and optimize solutions were taken to save energy, response time and to minimize the cost and flexibility using mobile cloud computing.

\section{References}

[1] Othman, Mazliza, Abdul Nasir Khan, Shahbaz Akhtar Abid, and Sajjad Ahmad Madani. "MobiByte: an application development model for mobile cloud computing." Journal of Grid Computing 13, no. 4 (2015): 605-628U.

[2] Gupta, Abhishek Kumar. "Challenges in mobile computing." In Proceedings of 2nd National Conference on Challenges and Opportunities in Information Technology (COIT-2008). Mandi Gobindgarh, India: RIMT-IET, pp. 86-90. 2008.

[3] Katyal, Mayanka, and Atul Mishra. "A comparative study of load balancing algorithms in cloud computing environment." arXiv preprint arXiv:1403.6918 (2014)

[4] Buyya, Rajkumar, Chee Shin Yeo, Srikumar Venugopal, James Broberg, and Ivona Brandic. "Cloud computing and emerging IT platforms: Vision, hype, and reality for delivering computing as the 5th utility." Future Generation computer systems 25, no. 6 (2009): 599-616.

[5] Jawaligi, Shivkumar S., and G. S. Biradar. "Single Mobile Sink Based Energy Efficiency and Fast Data Gathering Protocol for Wireless Sensor Networks." Wireless Sensor Network 9, no. 04 (2017): 117.

[6] Monfared, Alireza K., Ellen W. Zegura, Mostafa Ammar, David Doria, and David Bruno. "Computational ferrying: Efficient scheduling of computation on a mobile high performance computer." Computer Communications 96 (2016): 110-122.

[7] Huang D, Wang P, Niyato D. A dynamic offloading algorithm for mobile computing. IEEE Transactions on Wireless Communications. 2012 Jun;11(6):1991-5.

[8] Ou, Shumao, Kun Yang, and Jie Zhang. "An effective offloading middleware for pervasive services on mobile devices." Pervasive and Mobile Computing 3.4 (2007): 362-385.

[9] Ou, Shumao, Kun Yang, Antonio Liotta, and Liang $\mathrm{Hu}$. "Performance analysis of offloading systems in mobile wireless environments." In Communications, 2007. ICC'07. IEEE International Conference on, pp. 1821-1826. IEEE, 2007.

[10] Liu, Qi, Weidong Cai, Jian Shen, Xiaodong Liu, and Nigel Linge. "An adaptive approach to better load balancing in a consumercentric cloud environment." IEEE Transactions on Consumer Electronics 62, no. 3 (2016): 243-250.

[11] Ray, Soumya, and Ajanta De Sarkar. "Execution analysis of load balancing algorithms in cloud computing environment." International Journal on Cloud Computing: Services and Architecture (IJCCSA) 2.5 (2012): 1-13.
[12] Abolfazli, Saeid, Zohreh Sanaei, Mojtaba Alizadeh, Abdullah Gani, and Feng Xia. "An experimental analysis on cloud-based mobile augmentation in mobile cloud computing." IEEE Transactions on Consumer Electronics 60, no. 1 (2014): 146-154.

[13] Namboodiri, Vinod, and Toolika Ghose. "To cloud or not to cloud: A mobile device perspective on energy consumption of applications." In World of Wireless, Mobile and Multimedia Networks (WoWMoM), 2012 IEEE International Symposium on a, pp. 1-9. IEEE, 2012.

[14] Alnezari, Amani S., and Nasser-Eddine Rikli. "Achieving Mobile Cloud Computing through Heterogeneous Wireless Networks." International Journal of Communications, Network and System Sciences 10, no. 06 (2017): 107.

[15] Padma, Y., K. Pavan Kumar, and A. Durgabhavani. "A simple analysis of service oriented architecture for mobile cloud computing." In IEEE J, vol. 11, no. 1. 2014.

[16] Itani, Wassim, Ayman Kayssi, and Ali Chehab. "Energy-efficient incremental integrity for securing storage in mobile cloud computing." In Energy Aware Computing (ICEAC), 2010 International Conference on, pp. 1-2. IEEE, 2010.

[17] Nguyen, Anh-Dung, Patrick Sénac, and Victor Ramiro. "How mobility increases mobile cloud computing processing capacity." In Network Cloud Computing and Applications (NCCA), 2011 First International Symposium on, pp. 50-55. IEEE, 2011.

[18] Shiraz, Muhammad, Abdullah Gani, Azra Shamim, Suleman Khan, and Raja Wasim Ahmad. "Energy Efficient Computational Offloading Framework for Mobile Cloud Computing." J. Grid Comput. 13, no. 1 (2015): 1-18.

[19] Chen, Meng-Hsi, Ben Liang, and Min Dong. "A semidefinite relaxation approach to mobile cloud offloading with computing access point." In Signal Processing Advances in Wireless Communications (SPAWC), 2015 IEEE 16th International Workshop on, pp. 186-190. IEEE, 2015.

[20] Chen, Xu. "Decentralized computation offloading game for mobile cloud computing." IEEE Transactions on Parallel and Distributed Systems 26, no. 4 (2015): 974-983.

[21] Xia, Feng, Fangwei Ding, Jie Li, Xiangjie Kong, Laurence T. Yang, and Jianhua Ma. "Phone2Cloud: Exploiting computation offloading for energy saving on smartphones in mobile cloud computing." Information Systems Frontiers 16, no. 1 (2014): 95111.

[22] Wu, Huaming, Qiushi Wang, and Katinka Wolter. "Tradeoff between performance improvement and energy saving in mobile cloud offloading systems." In Communications Workshops (ICC), 2013 IEEE International Conference on, pp. 728-732. IEEE, 2013.

[23] Wang, Cheng, and Zhiyuan Li. "Parametric analysis for adaptive computation offloading." In ACM SIGPLAN Notices, vol. 39, no. 6, pp. 119-130. ACM, 2004.

[24] Shahzad, Haleh, and Ted H. Szymanski. "A dynamic programming offloading algorithm for mobile cloud computing." In Electrical and Computer Engineering (CCECE), 2016 IEEE Canadian Conference on, pp. 1-5. IEEE, 2016.

[25] Liu, Yanchen, and Myung J. Lee. "An effective dynamic programming offloading algorithm in mobile cloud computing system." In Wireless Communications and Networking Conference (WCNC), 2014 IEEE, pp. 1868-1873. IEEE, 2014.

[26] Guo, Songtao, Bin Xiao, Yuanyuan Yang, and Yang Yang. "Energy-efficient dynamic offloading and resource scheduling in mobile cloud computing." In Computer Communications, IEEE 
INFOCOM 2016-The 35th Annual IEEE International Conference on, pp. 1-9. IEEE, 2016.

[27] Cuervo, Eduardo, Aruna Balasubramanian, Dae-ki Cho, Alec Wolman, Stefan Saroiu, Ranveer Chandra, and Paramvir Bahl. "MAUI: making smartphones last longer with code offload." In Proceedings of the 8th international conference on Mobile systems, applications, and services, pp. 49-62. ACM, 2010.

[28] Hassan, Mohammed A., Kshitiz Bhattarai, Qi Wei, and Songqing Chen. "Pomac: Properly offloading mobile applications to clouds." Energy (J) 25 (2014): 50.

[29] Li, Jiwei, Kai Bu, Xuan Liu, and Bin Xiao. "Enda: Embracing network inconsistency for dynamic application offloading in mobile cloud computing." In Proceedings of the second ACM SIGCOMM workshop on Mobile cloud computing, pp. 39-44. ACM, 2013.

[30] Atta ur Rehman Khan, Mazliza Othman, Sajjad Ahmad Madan and Samee Ullah Khan I . "A Survey of Mobile Cloud Computing Application Models." IEEE ,2014

[31] Forman, George H., and John Zahorjan. "The challenges of mobile computing." Computer 27, no. 4 (1994): 38-47.

[32] Gupta, S. K. S., and P. K. Srimani. "Experience in teaching a graduate course in mobile computing." In Frontiers in Education Conference, 2000. FIE 2000. 30th Annual, vol. 2, pp. S1C-6. IEEE, 2000.

[33] Abolfazli, Saeid, Zohreh Sanaei, Ejaz Ahmed, Abdullah Gani, and Rajkumar Buyya. "Cloud-based augmentation for mobile devices: motivation, taxonomies, and open challenges." IEEE Communications Surveys \& Tutorials 16, no. 1 (2014): 337-368. 